\title{
Rancangan Media Penyimpanan Berbasis Mikrokontroler Menggunakan Raspberry Pi sebagai Mini Server Portabel
}

\author{
Tengku Mohd Diansyah ${ }^{1}$, Elza llyanda ${ }^{2}$ \\ UniversitasHarapan,ProgramStudiTeknik Informatika,Medan,Indonesia ${ }^{1,2,3}$ \\ Email : Dian.10.22@gmail.com¹, elzailyanda@gmail.com ${ }^{2}$
}

\begin{abstract}
Pada saat ini teknologi kabel sudah tidak banyak digunakan lagi, karena teknologi nirkabel memungkinkan pengguna menggunakan media penyimpanan dengan lebih efesien. Aplikasi media penyimpanan mini berbasis mikrokontroler dengan raspberry pi sebagai server dimaksudkan untuk mempermudah pengguna dalam penyimpanan data karena bersifat portabel. Hardware yang diimplementasikan menggunakan metode client server dalam arsitekturnya. Dari hasil percobaan dapat disimpulkan bahwa server raspberry pi yang telah dibangun tidak dapat menumpung terlalu banyak user karena spesifikasi dari raspberry pi yang masih tergolong rendah. Setelah dianalisa diketahui bahwa setelah 10 user mengakses server raspberry pi secara bersamaan maka salah satu perangkat dari user akan mengalami Request Time Out atau biasa disebut error page. Oleh sebab itu kiranya perlu mengupgrade hardware raspberry pi ke versi terbaru yang peformanya lebih unggul agar dapat menampung lebih banyak user untuk mengakses server secara bersama-sama.
\end{abstract}

Kata kunci: Client Server, Raspberry Pi,Mini Server.

\section{LatarBelakang}

Pada saat ini teknologi kabel sudah tidak banyak digunakan lagi, karena teknologi nirkabel memungkinkan pengguna menggunakan media penyimpanan dengan lebih efesien. Istilah Server Computing mulai banyak didengar dan perkembangannya sangat luar biasa. Untuk membangun sebuah server membutuhkan biaya yang cukup besar. Namun, keterbatasan biaya menjadi salah satu kendala dalam membangun sebuah server. Raspberry Pi adalah komputer berukuran mini dengan biaya yang tergolong murah dan dapat menjadi sebuah server portable. Raspberry Pi merupakan salah satu solusi ketika kita ingin membangun server dengan cakupan area kecil.
Ada beberapa penelitian yang sebelumnya dilakukan dengan menggunakan Raspberry Pi. Penelitian tersebut dilakukan oleh :

(1) Avorinzano Arry dan Fajar Ahmad (2013) dengan judul "Penggunaan Raspberry Pi sebagai alternatif Micro Controller pada Robot sederhana" Kedua peneliti ini telah membuat robot dengan menggunakan Raspberry Pi. Alat ini digunakan sebagai pengendali atau pengontrol yang bertugas memberi intruksi terhadap kinerja robot.

(2) Sholehudin dan Asmunin (2016) dalam jurnal yang berjudul "Mirroring Cloud Storage menggunakan Owncloud untuk akses, Sinkronisasi, dan Share Data" menceritakan tentang perkembangan teknologi penyimpanan berbasis. Tujuan penggunaan Raspberry $P i$ ini adalah sebagai media penyimpanan server data. 
Jurnal Penelitian Teknik Informatika

Universitas Prima Indonesia (UNPRI) Medan
Volume 1 Nomor 1, April 2018 e-ISSN : 2541-2019
Dari sumber literature review di atas, peneliti dapat mengetahui bahwa penelitian tentang Media Penyimpanan Mini Berbasis Mikrokontroller dengan Raspberry Pi Sebagai Server Portable belum pernah dilakukan.

\section{Metode}

\subsection{Server}

Server dalam dunia komputer adalah sebuah sistem komputer yang menyediakan jenis layanan tertentu dalam sebuah jaringan komputer. Server didukung dengan prosesor yang bersifat scalable dan RAM yang besar, juga dilengkapi dengan sistem operasi khusus, yang disebut sebagai sistem operasi jaringan atau network operating system. Server juga menjalankan perangkat lunak administratif yang mengontrol akses terhadap jaringan dan sumber daya yang terdapat di dalamnya, seperti halnya berkas atau alat pencetak (printer), dan memberikan akses kepada workstation anggota jaringan. Umumnya, di atas sistem operasi server terdapat aplikasi-aplikasi yang menggunakan arsitektur client/ server. Contoh dari aplikasi ini adalah DHCP (Dynamic Host Configuration Protocol) Server, Mail Server, HTTP (Hyper Text Transfer Protocol) Server, FTP (File Transfer Protocol) Server, DNS (Domain Name System) Server dan lain sebagainya. [3]

\subsection{Protokol}

Protokol adalah spesifikasi formal yang mendefinisikan prosedur-prosedur yang harus diikuti ketika mengirim dan menerima data. Protokol mendefinisikan jenis, waktu, urutan dan pengecekan kesalahan yang digunakan dalam jaringan. [6]

\subsection{IP Address}

TCP/IP (modular) adalah sekumpulan protokol yang didesain untuk melakukan fungsi-fungsi komunikasi data pada wide Area Network (WAN). TCP/IP terdiri dari sekumpulan protokol yang masing-masing bertanggung jawab atas bagian-bagian tertentu dari komunikasi data.

Berkat penggunaan prinsip modular ini, TCP/IP menjadi protokol komunikasi data yang fleksibel. Protokol TCP/IP dapat diterapkan dengan mudah di setiap jenis komputer dan interface jaringan, karena sebagian besar isi kumpulan protokol ini tidak spesifik terhadap satu komputer atau peralatan jaringan tertentu. Agar TCP/IP dapat berjalan di atas interface jaringan tertentu, hanya perlu dilakukan perubahan pada protokol yang berhubungan dengan interface jaringan saja. [7]

\subsection{Raspberry Pi}

Raspberry Pi diluncurkan pertama kali pada 29 Februari 2012. Raspberry Pi memiliki dua model, model A dan model B. Harga Resmi untuk model A adalah US\$ 25 atau sekitar Rp 250.000 dan model B adalah US\$ 35 atau sekitar Rp 350.000 (belum termasuk biaya impor dan pajak ke Indonesia). Perbedaan model A dan B terletak pada memory yang digunakan. Model A menggunakan memory 256 MB dan model B 512 MB. Selain itu model B juga sudah dilengkapai dengan ethernet port (kartu jaringan) yang tidak terdapat di model A. Ada beberapa sistem operasi luar biasa yang bisa digunakan di Raspberry pi, yaitu Linux Debian, Arch Linux ARM, Raspbmc, OpenELEC dan Android. [8]

Raspberry Pi adalah sebuah processor Advanced RISC Machine/Acorn RISC Machine (ARM) dapat menjalankan sistem operasi berbasis Linux atau sistem operasi ringan lainnya. Raspberry Pi sudah memiliki beberapa port seperti port High Definition Multimedia Interface (HDMI), port Radio Corporation of America (RCA) video, port audio, port ethenet, dan port Universal Serial Bus (USB) 2.0 [9]. Berikut gambar Raspberry pitipe $\mathrm{A}+$ dan $\mathrm{B}+$.

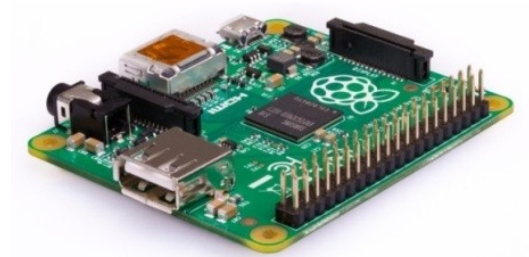

Gambar .1Tampilan Board Raspberry Pi tipe $A+$ Sumber: [15]

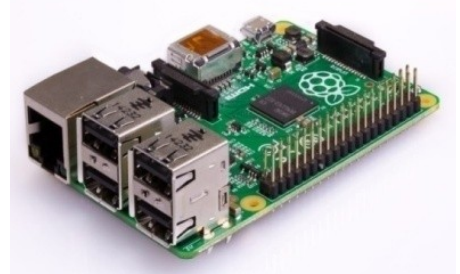

Gambar 2 Tampilan Board Raspberry Pi B+ Sumber: [15]

\subsection{Raspbian}

Raspbian adalah sistem operasi lengkap berbasis Linux, tersedia secara bebas dan mempunyai dukungan, baik yang berasal dari komunitas maupun tenaga ahli profesional. Raspbian merupakan sistem operasi turunan dari distro Linux Debian. Raspbian semakin diminati oleh 
para penggunanya sebagai sistem operasi untuk Raspberry Pi karena sistem operasi ini berbasis Debian dan open source [2].

\subsection{Owncloud}

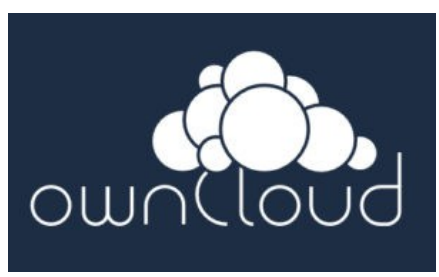

Gambar 3 Logo Owncloud

Sumber: [18]

OwnCloud merupakan suatu perusahaan dengan proyeknya yaitu OwnCloud project dengan slogan Your Cloud, Your Data, Your Way!. OwnCloud yang merupakan salah satu perangkat lunak berbagi berkas gratis dan berbasis open source, menyediakan pengamanan yang baik, memiliki tata cara yang baik bagi pengguna aplikasi untuk membagi dan mengakses data yang secara lancar terintegrasi dengan perangkat teknologi informasi yang tujuannya mengamankan, melacak, dan melaporkan penggunaan data. [2]

\section{ANALISIS DAN PERANCANGAN SISTEM}

\subsection{Analisis Sistem}

Analisis sistem dapat didefinisikan sebagai penguraian dari suatu sistem yang utuh ke dalam bagian-bagian komponennya dengan maksud untuk mengidentifikasikan dan mengevaluasi permasalahan sehingga ditemukan kelemahan-kelemahannya, kesempatan-kesempatan, hambatan-hambatan, yang terjadi dan kebutuhankebutuhan yang diharapkan sehingga dapat diusulkan perbaikannya. Analisis bertujuan untuk mendapatkan pemahaman secara keseluruhan tentang sistem yang akan dibuat berdasarkan masukan dari pihak-pihak dan juga pengalaman analisis yang berkepentingan dengan sistem tersebut.

\subsection{Perancangan Sistem}

Dalam perancangan sistem ini media penyimpanan mini menggunakan raspberry pi sebagai server portable nantinya dapat diakses oleh client menggunakan web browser.

Adapun network diagram yang menjadi gambaran langkah awal yang dilakukan oleh client adalah sebagai berikut:

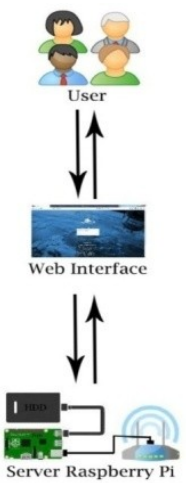

Gambar 4 Network Diagram Proses Sistem

Gambar di atas adalah langkah awal yang dilakukan oleh client dalam mengakses media penyimpanan tersebut melalui web browser sebagai interface, untuk lebih detailnya perhatikan flowchart sistem kerja berikut ini:

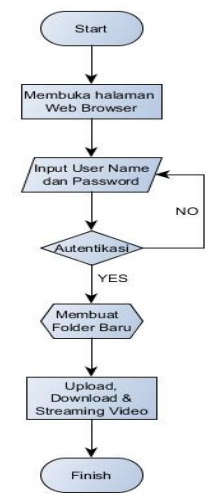

Gambar 5 Flowchart Sistem Kerja

Gambar flowchart diatas memberi intruksi bahwa langkah awal yang dilakukan oleh admin atau user adalah membuka halaman web browser serta memasukkan user name dan password pada halaman web browser, kemudian sistem akan melakukan autentikasi jika data yang dimasukkan benar maka pengguna dapat masuk ke halaman utama dan dapat melakukan upload, download, serta streaming video.

\section{PENGUJIAN SISTEM DAN IMPLEMENTASI 4.1 Pengujian Server}

Sebelum dilakukan pengujian ada beberapa tahap yang harus dilakukan agar proses pengujian dan menganalisa data dilakukan dengan baik. Adapun tahap-tahap yang dilakukan adalah sebagai berikut.

- Pastikan semua perangkat server telah terhubung. 


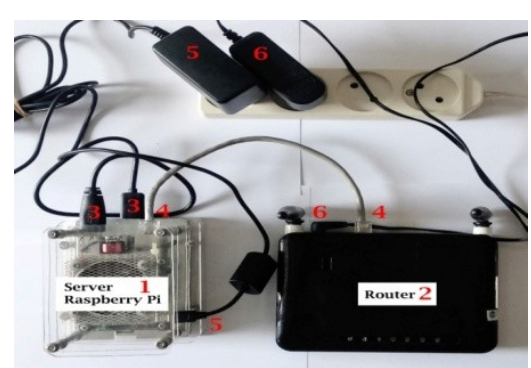

Gambar 6 Perangkat server

Gambar diatas adalah perangkat server yang telah terhubung, lebih detailnya penulis menjabarkan fungsi dari masing-masing hardware diatas antara lain:

1. Perangkat raspberry pi yang berfungsi sebagai media web server.

2. Perangkat Router yang berfungsi sebagai penghubung antara server dengan client. Pada penelitian ini penulis menggunakan Router D-link Tipe DWR-116.

3. Perangkat Hardisk external yang berfungsi sebagai media penyimpanan dan terhubung dengan Raspberry Pi melalui port USB.

4. Perangkat Kabel UTP adalah media yang menghubungkan antara Raspberry Pidengan Router.

5. Power adaptor yang menjadi sumber suply daya untuk Raspberry Pi, adaptor tersebut menyediakan arus sebesar 5V/2.5A dan termaksud standar arus yang dibutuhkan oleh Raspberry Pi.

6. Power adaptor yang menjadi sumber suply daya untuk Router, adaptor tersebut menyediakan arus sebesar 5V/2A dan termaksud standar arus yang dibutuhkan oleh Router.

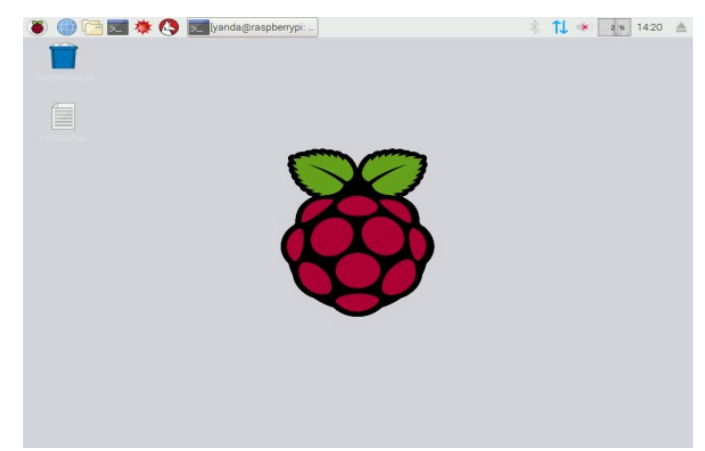

Gambar. 7 Tampilan Desktop Rasbian

Gambar diatas adalah tampilan dari desktop raspberry pi yang digunakan sebagai server. Maka dari itu perlu dipastikan agar semua proses dan running service pada raspberry pi berjalan dengan lancar tanpa ada error, untuk mengecek status dari running service dapat menggunakan perintah \#service --status-all pada terminal raspberry pi, running service yang digunakan pada server raspberry pi yaitu nginx, php7.0, varnish, memcached \& ssh. Seperti gambar berikut ini.

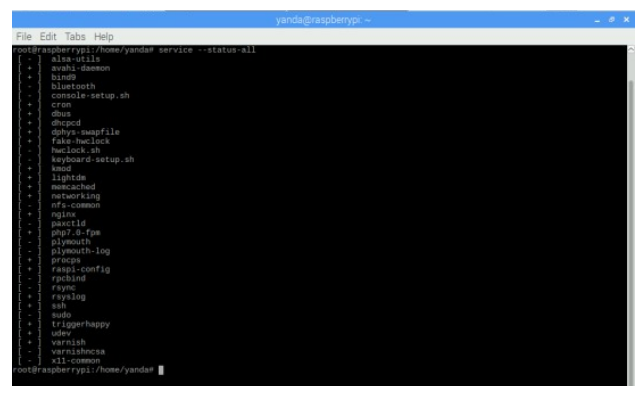

Gambar 8 Start-up service Raspberry Pi

\subsection{Implementasi Aplikasi}

Pengujian aplikasi dapat dilihat melalui web browser. Ketika aplikasi dijalankan maka akan tampak halaman Index sebagai halaman utama setelah client melakukan login.

\subsubsection{Halaman Login}

Halaman login akan terbuka setelah client memasukkan alamat IP pada web browser, ip yang dimasukkan pada gambar dibawah ini yaitu 22.94.3.50.

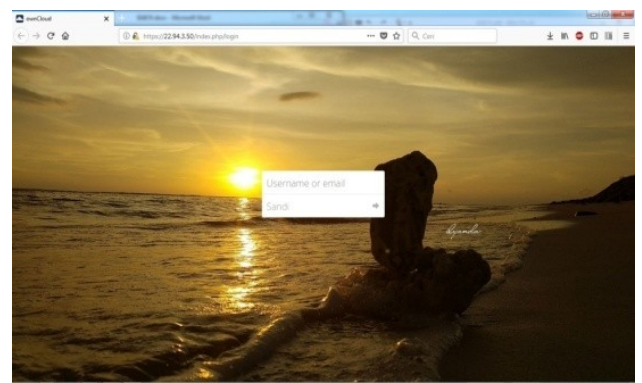

Gambar 9 Tampilan halaman login

\subsubsection{Halaman Berkas}

Halaman Berkas, pada halaman ini client dapat menambah folder, upload file, download file, view file serta delete file seperti gambar dibawah ini. 


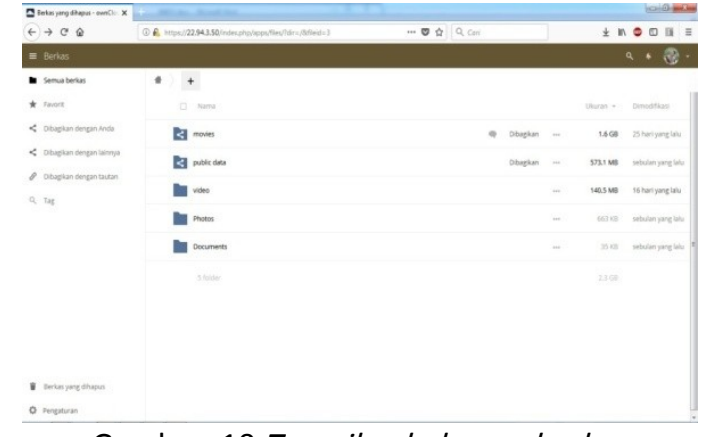

Gambar 10 Tampilan halaman berkas

\subsubsection{Streaming Video}

Pada streaming video ini client dapat menonton video dihalaman berkas dari video-video yang telah diupload oleh client seperti gambar berikut ini.

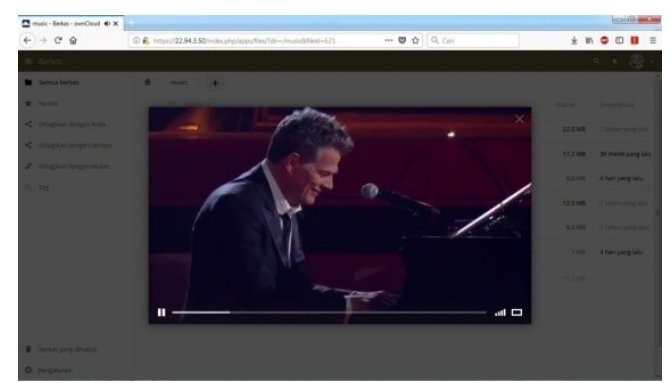

Gambar 11 Tampilan halaman streaming video

\subsubsection{Halaman Edit Profil}

Pada halaman edit profil ini client dapat melakukan edit profil data dirinya yang meliputi ubah nama, ubah foto, ubah password dan menambahkan e-mail pada akun tersebut seperti pada gambar berikut ini.

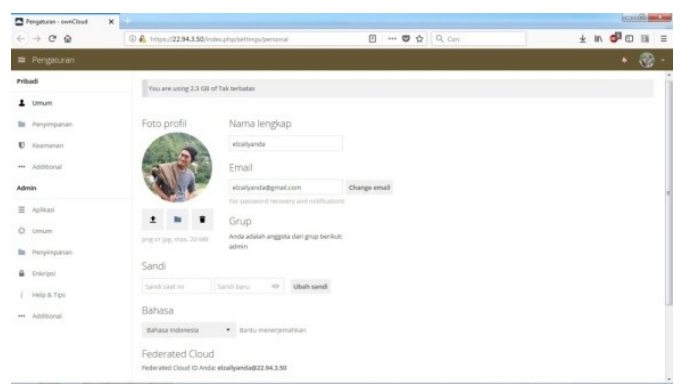

Gambar 12 Tampilan halaman Edit Profil

\subsubsection{Halaman Tambah User}

Pada halaman tambah user ini hanya dapat diakses oleh akun admin, halaman tambah user ini adalah untuk menambah data user baru yang harus diinputkan adalah nama, password dan grup, kemudian admin juga dapat menetapkan besaran kuota yang diberikan kepada user yang dibuatnya seperti gambar berikut ini.

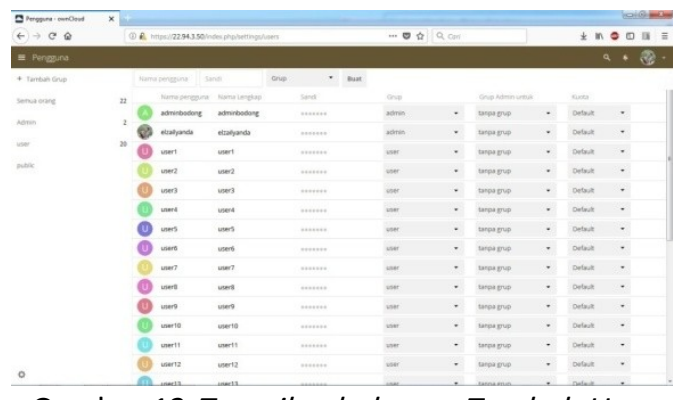

Gambar 13 Tampilan halaman Tambah User

Dari hasil percobaan dan analisa sistem, penulis dapat mengambil kesimpulan bahwa server raspberry pi yang telah dibangun tidak dapat menumpung terlalu banyak user karena spesifikasi dari raspberry pi yang masi tergolong rendah, setelah melakukan uji coba penulis menganalisa bahwa setelah 10 user mengakses server raspberry pi secara bersamaan maka salah satu perangkat dari user akan mengalami Request Time Out atau biasa disebut error page. Maka dari itu perlunya mengupgrade hardware raspberry pi ke versi terbaru yang peformanya lebih unggul agar dapat menampung lebih banyak user untuk menggakses server secara bersama-sama.

\section{KESIMPULAN DAN SARAN}

\subsection{Kesimpulan}

Berdasarkan hasil yang telah diperoleh dapatlah diambil kesimpulan sebagai berikut:

1. Sistem penyimpanan dapat diakses banyak user secara bersamaan untuk melakukan upload, dan download data.

2. Sistem interface yang dibangun adalah owncloud menggunakan perangkat raspberry sebagai server yang berbentuk mini sehingga pengguna dapat dengan mudah membawa perangkat kemana saja.

3. Spesifikasi raspberry pi yang masih tergolong rendah sehingga membuat server raspberry pi menjadi lambat ketika diakses.

4. Pada saat pengujian sistem dapat diambil kesimpulan bahwa saat sepuluh user melakukan transfer data secara bersamaan akan terjadi Time Out pada halaman webpage beberapa perangkat.

\subsection{Saran}


Sesuai dengan kesimpulan yang telah dipaparkan diatas, saran yang dapat diberikan yakni:

1. Spesifikasi dari raspberry pi masih sangat rendah sehingga belum dapat menampung terlalu banyak user, maka dari itu perlunya upgrade raspberry pi dengan metode cluster sehingga kedepanya diharapkan sistem menjadi mini server yang dapat menampung banyak user.

2. Sistem ini dapat dikembangkan oleh sekolah umum dan mendukung program pemerintah dengan UNBK (Ujian Nasional Berbasis Komputer).

\section{DAFTAR PUSTAKA}

[1] Andriyanto, Irwin. 2016. Struktur Dasar Algoritma.https://www. masirwin.com/strukturdasar-algoritma/. Diakses 24 Maret 2018.

[2] Aisa, S., \& R, T. 2016. Implementasi Private Cloud Menggunakan Raspberry Pi Untuk Pengaksesan Data Pribadi. Jurnal Penelitian Pos dan Informatika, Vol 6 No 2. Desember 2016. E-ISSN: 2476-9266

[3] Aprianti, W., \& Maliha, U. 2016. Sistem Informasi Kepadatan Penduduk Keluaran Desa Studi Kasus Pada Kecamatan Bati-bati Kabupaten Tanah Laut. Jurnal Sains dan Informatika, Vol 2 No 1, Juni 2016. E-ISSN: 2460-173X

[4] Bahri, Khaerul. 2016. Pengertian dan macam-macam media penyimpanan data komputer.https://www.levatra.com/2016/05/penger tian-macam-media-penyimpanan-data.html. Diakses 03 Februari 2018.

[5] S. Rumalutur, "Analisis Keamanan Jaringan Wireless LAN (WLAN) Pada PT.PLN (Persero) Wilayah P2B Area Sorong," vol. 19, no. 100, hal. 48-60.

[6] S. Hidayatulloh, "Analisis dan optimalisasi keamanan jaringan menggunakan protokol ipsec," vol. I, no. 2, hal. 93-104, 2014.

[7] O. W. Purbo, Internet-TCP/IP Konsep \& Implementasi. Yogyakarta: Andi, 2018.

[8] A. Krisnawan, "Perancangan Sistem Keamanan Ruangan Menggunakan," vol. 2, no. 2, hal. 38223828, 2015.

[9] S. Aisa dan T. R, "Implementasi Private Cloud Menggunakan Raspberry Pi Untuk Pengaksesan Data Pribadi," vol. 6, no. 2, hal. 137-152, 2016.

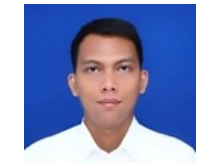

Tengku Mohd Diansyah, ST, M.Kom Lahir di Pontianak,22 Oktober 1988. Pendidikan Strata1(S1)Program Studi Teknik Informatika di Sekolah Tinggi Teknik Harapan (STTH) Medan danS trata2 (S2) Magister IImu Komputer Program Studi IImu Komputer diPasca sarjana Universitas Putra Indoensia (YPTK) Padang. Penulis dibeberapa jurnal dan Dosen di Universitas Harapan Medan dari tahun2012.

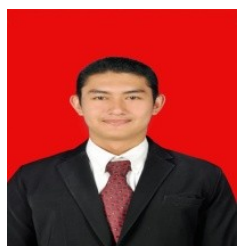

Elza Ilyada, S.Kom Lahir di Medan, 22 Maret 1994. Pendidikan Strata1 (S1) Program Studi Teknik Informatika Universitas Harapan. Berminat di Bidang system Jaringan. 